\title{
O uso da fitoterapia no cuidado de crianças com até cinco anos em área central e periférica da cidade de São Paulo
}

\author{
THE USE OF PHYTOTHERAPY IN THE CARE OF CHILDREN UP TO 5 YEARS OF AGE IN \\ URBAN AND SUBURBAN AREAS OF SÃO PAULO CITY-BRAZIL

\section{EL USO DE LA FITOTERAPIA EN EL CUIDADO DE NINÕS MENORES DE CINCO AÑOS EN ÁREAS CENTRAL Y PERIFÉRICA DE LA CIUDAD DE SÃO PAULO-BRASIL}

\section{Andréa Regiani Alves ${ }^{1}$, Maria Júlia Paes da Silva ${ }^{2}$}

\author{
RESUMO \\ Esta pesquisa verifica a \\ utilização da fitoterapia em \\ crianças que freqüentam um \\ centro de saúde da área \\ central e um centro de saúde \\ da periferia da cidade de São \\ Paulo. É um estudo \\ exploratório descritivo, com \\ 120 mães que freqüentam os \\ dois centros de saúde (sendo \\ 60 na região central e 60 na \\ região periférica) durante $o$ \\ mês de dezembro de 2001. \\ Após aprovação pelo Comitê \\ de Ética, as mães foram \\ questionadas individualmente \\ e verificamos que 79 (66\%) \\ delas utilizam com maior \\ freqüencia a camomila, a \\ erva-doce e a hortelã para \\ cólicas intestinais, sintomas \\ de gripe e tranqüilizar seus \\ filhos. As informações sobre \\ como e o que utilizar vieram, \\ segundo as mães, \\ principalmente de pais e avós \\ $45(57 \%)$ e, concluindo, não \\ encontramos grandes \\ diferenças entre o uso nas \\ duas regiões de São Paulo.
}

\section{PALAVRAS-CHAVE}

Terapias alternativas.

Fitoterapia.

Enfermagem pediátrica.

\begin{abstract}
This research evaluated the use of phytotherapy in children who attend a Health Center in an urban area and a Health Center in the suburbs of São Paulo city. This is an exploratory and descriptive study with 120 mothers who attend two Health Centers (60 mothers in the urban area and another 60 in the suburbs), during December 2001. After receiving approval from the Ethics Committee, the mothers were individually interviewed and it was confirmed that 79 (66\%) of them frequently used chamomile, fennel and peppermint for the intestinal cramps, flu symptoms and to calm their children down. Directions on how and what to use was provided mainly by parents and grandparents (57\%) and no great differences could be found in the use of herbs in the two areas of São Paulo.
\end{abstract}

\section{KEYWORDS}

Alternative therapies

phytoterapy.

Pediatric nursing.

\section{RESUMEN}

El uso de la fitoterapia en el cuidado de ninõs menores de cinco años en áreas central y periférica de la ciudad de São Paulo.Esta investigación constató la utilización de la fitoterapia en ninõs que acuden a un centro de salud del área central y a un centro de salud de la periferia de São Paulo. Es un estudio exploratorio descriptivo, con 120 madres que acudieron a los dos centros de salud (60 en la región central y 60 en la región periférica) durante el mes de diciembre de 2001. Después de la aprobación por el Comité de Ética, las madres fueron preguntadas individualmente y verificamos que el 79 (66\%) de ellas utilizam con mayor frecuencia la manzanilla, el anís y la hierba buena para los cólicos intestinales, sintomas de gripe y tranquilizante para sus hijos. Las informaciones sobre cómo y qué utilizar, vinieron principalmente de padres $y$ abuelos 45 (57\%) y no encontramos gran diferencia entre el uso de las hierbas en las regiones de São Paulo.

\section{PALABRAS CLAVE}

Terapias Alternativas.

Fitoterapia.

Enfermería Pediatríca.
1 Aluna do $5^{\circ}$ semestre de Enfermagem pela Escola de Enfermagem da USP (EEUSP). andrearegiani@ig.com.br 2 Professora Associada do Deptartamento de Enfermagem MédicoCirúrgica da EEUSP. juliaps@usp.com.br 


\section{INTRODUÇÃO}

Fitoterapia consiste no uso interno ou externo de vegetais "in natura" ou sob a forma de medicamentos no tratamento de doenças ${ }^{(1-9)}$. Para Hipócrates a saúde significa a harmonia do homem com a natureza, o equilíbrio entre os diversos componentes do organismo entre si e o meio ambiente. Saúde e doença dependem da interação da mente com o corpo e do homem com o meio em que vive $^{(10)}$

Vestígios geológicos evidenciam que a utilização de plantas como meio de tratamento pelo homem remontam mais de cinco mil anos. Uma vez que os animais silvestres raramente se enganam na capacidade de distinguir as plantas de espécies alimentares das tóxicas, acredita-se que a observação do comportamento dos animais contribuiu para que o homem pré-histórico descobrisse as propriedades curativas das plantas. O homem então, imitando os animais, aprendeu desde cedo o valor curativo das plantas, percebendo que algumas eram terapêuticas e outras venenosas $^{(8)}$.

No Brasil, o emprego de ervas medicinais era prática indígena, que somado a outras práticas trazidas por escravos africanos e pelos portugueses, geraram uma rica cultura popular $^{(8)}$.

Com o advento da medicina alopata esse método de cura foi deixado de lado até que, devido aos efeitos colaterais ou devido ao alto custo dos medicamentos, a fitoterapia foi novamente colocada em destaque ${ }^{(11)}$. Vale lembrar que, apesar de ser um método barato e não-agressivo, pode causar efeitos colaterais quando utilizada de forma incorreta, como relatam enfermeiras de Pronto Socorros que encontraram pacientes intoxicados ou com crise de hipertensão, quando misturaram, por exemplo, ephedra e cafeína ${ }^{(7)}$. Para evitar esses efeitos e a utilização errada das plantas, muitas pesquisas científicas vêm sendo feitas a fim de alertar e indicar o uso correto de determinadas plantas ${ }^{(3-9,12)}$.

Já na década de 80, tiveram início pesquisas para verificar o uso de terapias alternativas de gestantes e mães em Centros de Saúde na cidade de São Paulo. Investigou-se sobre como eram utilizadas e sobre como eram obtidos os conhecimentos sobre as plantas medicinais. Constatou-se, que $84,6 \%$ das gestantes-mães, já tinham utilizado a fitoterapia para diversos males, incluindo tentativas de aborto (com sucesso ou não). Outras, porém, conheciam, mas não utilizavam, por não acreditarem ou por não encontrarem as plantas de que necessitavam ${ }^{(8)}$.

Outra pesquisa verificou a utilização de terapias alternativas por enfermeiros brasileiros e procurou descobrir o como, o por quê e o quê os enfermeiros utilizavam ou indicavam aos seus pacientes. A pesquisadora utilizou uma abordagem qualitativa, tipo estudo de casos e a coleta de dados partiu do discurso dos profissionais entrevistados. Os resultados apontaram que os enfermeiros utilizavam, cada vez mais, métodos alternativos no cuidado de pacientes. Destes, $12,5 \%$, utilizavam a fitoterapia como pratica alternativa, e a justificativa era a falta de credibilidade em recursos alopatas e a vontade de facilitar o cuidado e a manutenção da saúde de seus pacientes por um preço acessível a todos ${ }^{(11)}$.

No estado do Piauí, realizou-se um trabalho com mulheres - mães de crianças até cinco anos para comparar saberes científicos e populares no uso de plantas medicinais em condições de saúde-doença ${ }^{(5)}$. Essas mães tinham pouco contato com médicos, mas muito contato com farmácias vivas, criadas pela Universidade Federal do Ceará, a fimm de viabilizar a utilização de plantas medicinais àqueles que não tinham acesso a alopatia.

A pesquisadora apresentava às mães o desenho de uma árvore onde as mulheres colocavam a parte que era utilizada da planta, e o desenho de um corpo para descobrir onde eram utilizadas nas crianças. Complementava informações a essas mães, com o seu saber científico, o que caracterizou uma verdadeira troca de experiências. Ressaltou-se que a utilização das plantas medicinais como integrante dos programas de atenção básica em saúde pode ser uma alternativa terapêutica, porque tem baixo custo, havendo uma facilidade na aquisição e uma compatibilidade com a cultura da população atendida ${ }^{(5)}$.

A Organização Mundial da Saúde-OMS tem, desde 1976, como objetivos de seus programas de promoção de terapias alternativas, a consideração da chamada medicina tradicional, a difusão de praticas úteis e eficazes e a integração dos conhecimentos e das técnicas da medicina ocidental nos sistemas de medicina tradicional ${ }^{(13-15)}$. Em 1978, na Con- 
ferência de Alma-Ata, a OMS recomendou formalmente o estabelecimento de políticas nacionais de saúde baseadas na utilização dos recursos da medicina tradicional pelos sistemas nacionais de prestação de serviços de saúde ${ }^{(13)}$.

No Brasil, em 1986, no Relatório Final da VIII Conferência Nacional de Saúde, aparece pela primeira vez, em documento oficial, a proposta de introdução de práticas alternativas de assistência à saúde, no âmbito de serviços de saúde, possibilitando ao usuário o direito democrático de escolher a terapêutica preferida e a inclusão no currículo de ensino em saúde do conhecimento de praticas alternativas ${ }^{(2)}$.

Em 1995, o Conselho Federal de Enfermagem - COFEN - aprovou o parecer 004/95, que trata das atividades em terapias alternativas, fundamentando-se na visão holística de totalidade o ser humano. Esse parecer é favorável às Praticas de Terapias Naturais de Saúde por profissionais de Enfermagem, desde que estes possuam a comprovação de formação básica em tais terapias, proporcionando o desempenho seguro para si e para o cliente ${ }^{(16)}$.

A Secretaria Municipal de Saúde de São Paulo afirmou que pretendia implantar, até o final de 2001, a prática da medicina tradicional chinesa na rede estadual de atendimento. A proposta é criar centros para capacitação de funcionários interessados em trabalhar com tais práticas. Para isso, continua sendo feito um levantamento na própria rede, para identificar os profissionais já habilitados que constituirão a equipe de capacitação ${ }^{(6)}$.

Tendo como senso comum que a periferia é menos atendida alopaticamente, seja por dificuldade de acesso aos Centros de Saúde ou por falta de recursos para iniciar um tratamento, e que por isso se utiliza de espaços existentes no quintal da própria casa para o cultivo de plantas medicinais para o tratamento de doenças, essa pesquisa procurou comparar a utilização de plantas no cuidar de crianças com até cinco anos em regiões central e periférica da cidade de São Paulo, bem como verificar o que vem sendo mais usualmente utilizado por mães, nos seus filhos.

\section{OBJETIVOS DO TRABALHO}

- Verificar a utilização da fitoterapia em crianças que freqüentam Centros de Saúde na cidade de São Paulo;

- Comparar os dados encontrados em um centro de saúde da área central com um Centro de Saúde da periferia da cidade, quanto à utilização da fitoterapia em crianças.

\section{METODOLOGIA}

- Tipo de estudo: o estudo desenvolvido nesta pesquisa foi exploratório, descritivo e de campo.

- Local de estudo: o Centro de Saúde Paula Souza (região central) e o Centro de Saúde Dr. José Pires, Engenheiro Goulart (região leste).

- Amostra do estudo: mães de crianças com até cinco anos de idade que freqüentaram os 2 Centros de Saúde e que aceitaram participar do estudo no mês de dezembro de 2001. O total da amostra equivale a $30 \%$ das mães que freqüentaram os Centros de Saúde durante o mês, totalizando 60 mães em cada um dos Centros de Saúde. A amostra foi aleatória.

- Procedimentos de coleta dos dados: $\left.1^{\circ}\right)$ O projeto foi aprovado pelo Comitê de Ética e Pesquisa da Escola de Enfermagem da Universidade de São Paulo, no mês de outubro de 2001; $2^{\circ}$ ) Foi pedida a autorização à chefia dos dois centros de saúde e, após aprovação, foi solicitada a participação das mães que freqüentaram os Centros de Saúde, através de assinatura do Termo de Consentimento Livre e Esclarecido, onde constavam os objetivos da pesquisa, deixando claro sua liberdade de participação, seguindo as normas da Resolução 196/96 do Ministério da Saúde; $3^{\circ}$ ) As mães foram entrevistadas individualmente, usando-se um roteiro onde foi verificado o uso da fitoterapia como prática no cuidado de crianças até cinco anos, qual planta era utilizada, como teve acesso a esse conhecimento, a forma de utilização e o efeito conseguido (Anexo).

- Tratamento dos dados: Os dados coletados foram trabalhados quantitativamente através de freqüência e porcentagem.
O uso da fitoterapia no cuidado de crianças com até cinco anos em áreas central e periférica da cidade de São Paulo 


\section{ANÁLISE DOS DADOS}

A pesquisa foi realizada com mães de crianças de 1 mês até 5 anos que freqüentam as unidades básicas de saúde Paula Souza (central) - doravante chamada instituição A e José Pires (periférica) - doravante chamada instituição B, a média de idade encontrada nas crianças foi de 2,1 anos na instituição A e

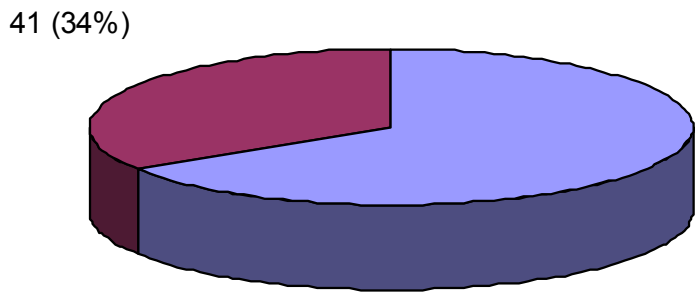

\section{$79(66 \%)$}

1,1 ano na instituição B. A média encontrada dos que utilizam a fitoterapia como prática de saúde foi de 2,4 anos na instituição A e 1,7 ano na instituição B.

Verificou-se que 79 (66\%) das mães afirmam utilizar plantas medicinais para o tratamento de doenças em seus filhos, como mostra a figura 1.

$\square$ Utiliza $\square$ Não Utiliza

Figura 1 - Utilização de plantas medicinais em crianças de até cinco anos em dois Centros de Saúde da cidade de São Paulo(São Paulo, 2001)

Notou-se que, em ambas as unidades, a quantidade de mães que utiliza plantas medicinais foi relativamente igual: $39(65 \%)$ na instituição A e 40 (66,6\%) na instituição B, o que revela que seu uso talvez não dependa da localização da população, mas sim do custo dos recursos alopatas ou da confiabilidade em recursos naturais que, segundo uma das mães entrevistadas: "faz bem, faz efeito sem agredir o organismo com substâncias industrializadas, além de custar mais barato". Por ser uma informação pontual, podemos supor que ela esteja relacionada também como uma das explicações possíveis para seu uso, considerando que todas as mães eram usuárias de serviços públicos de saúde e, portanto, talvez não diferissem tanto em relação ao poder de compra e, além disso, uma vez que fo- ram contatadas no serviço de saúde e não nos próprios domicílios, é possível que também não diferissem quanto a suas possibilidades de acesso ao serviço.

Devido à ampla utilização da fitoterapia, verifica-se com esse dado, o quão é importante o enfermeiro conhecê-la para melhor orientar a clientela que lhe é incumbida, seja na periferia ou no centro da cidade. Para saber algo, dominar uma prática é preciso conhecê-la; portanto o saber se constrói e reconstrói num movimento dinâmico, temporal e contínuo ${ }^{(5)}$.

Quando questionadas sobre quais plantas utilizam foram citados mais de 20 nomes vulgares de plantas, e os mais indicados estão na figura 2 .

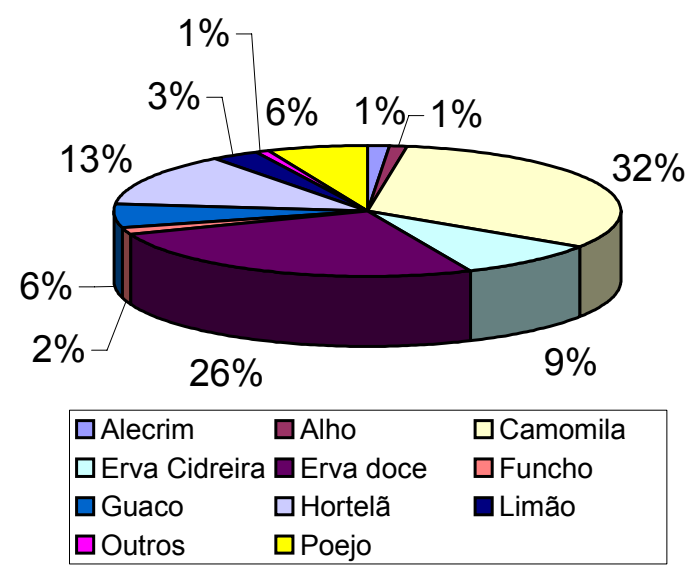


Foram, em primeiro lugar, citadas a camomila em ambas as instituições (30\% na A e $33 \%$ na B); em segundo a erva-doce com $28 \%$ na instituição A e $22 \%$ na instituição B; em terceiro aparece a Hortelã com $12 \%$ na instituição A e 13\% na instituição B. A camomila e a erva-doce são utilizadas para alívio da cólica e acalmar as crianças e a hortelã para aliviar sintomas de gripe.

Buscando o componente ativo dessas plantas encontra-se que a camomila tem efeito antiinflamatório e calmante, o que é coerente com o dito pelas mães sobre seu uso; a erva-doce beneficia o trabalho do estômago, reduzindo a produção de gases e ainda possui propriedades expectorantes. A hortelã tem efeito febrífugo, béquico, expectorante, antiespas-módico, estimulante digestivo, contribuindo para combater a prisão de ventre, o que revela que realmente alivia os sintomas da gripe, além de aliviar as cólicas intestinais também, como referem as mães entrevistadas ${ }^{(7-10,12-15,17)}$. Esta informação do que é mais utilizado em crianças pelas entrevistadas nos dois Centros de Saúde, indica ao enfermeiro quais as principais plantas que ele deve saber sobre seu uso, suas contraindicações e o modo de preparo.

Nos primeiros quatro meses de vida, o intestino não desenvolveu mecanismos de defesa que lhe permitam lidar com proteínas estranhas ou que não sejam do leite humano, o que revela que nesta idade é mais comum realmente os casos de cólica. Sabemos também que a rotina do sono da criança varia com as suas etapas evolutivas, bem como com as necessidades peculiares de cada criança individualmente ${ }^{(4)}$. Apesar de não termos coletado a idade exata que as crianças tinham quando tomaram chás, as mães afirmavam com freqüência que "tomaram muito chá quando eram bebezinhos...”.

Em relação ao aprendizado de como e o que usar da planta, 45 (57\%) das mães referiram tê-lo obtido em casa com os pais e avós (49\% na instituição A e 67\% na instituição B), ou seja, é um hábito cultural que tem se mantido através das gerações; em segundo lugar, há uma diferença, sendo que na instituição $\mathrm{A}$ (mais central) foi com vizinhos e amigos e na instituição B (periférica) o aprendizado ocorreu junto dos profissionais da área da saúde.

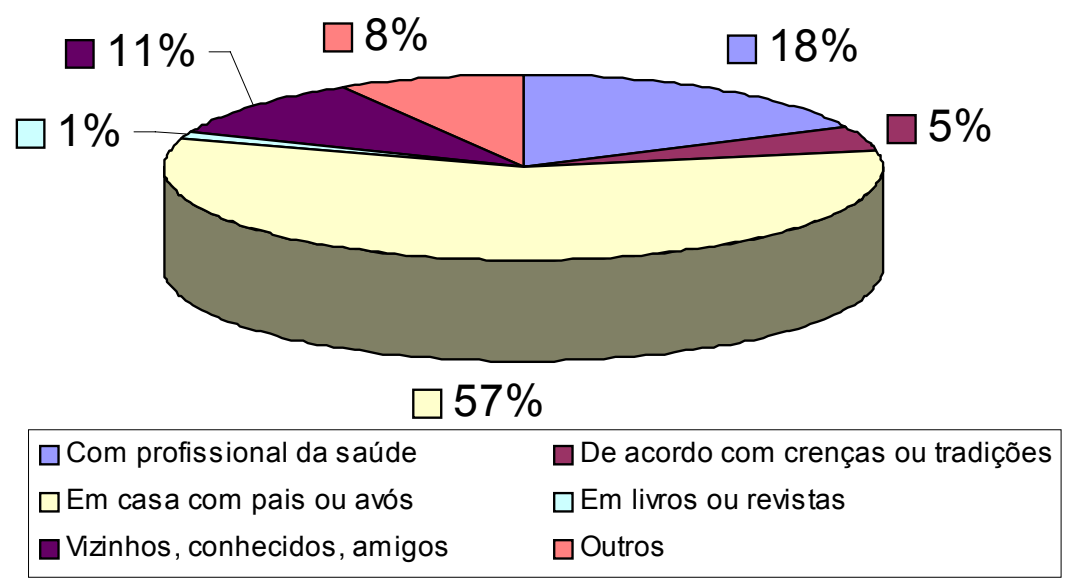

Figura 3 - Fonte do aprendizado sobre as plantas utilizadas em crianças de até cinco anos em dois Centros de Saúde da cidade de São Paulo (São Paulo, 2001)

A figura 3 revela que $18 \%$ das mães aprenderam o uso de fitoterapia através dos profissionais de saúde, o que ao nosso ver, é um bom sinal, pois inferimos que um profissional da saúde ao indicar o uso de uma planta, deve estar embasado em conhecimentos científicos para fazê-lo, pois ele está no papel de um profissional ao fazer a indicação.

O modo de utilizar as plantas citado pelas mães foi semelhante em ambas as instituições: $55(70 \%)$ chás, $16(20 \%)$ xaropes, $2(2 \%)$ cata- plasmas, 2 (2\%) óleos e os outros $6 \%$ de maneira variada. O chá mais utilizado é o de camomila, feito da flor, mostrando que o conhecimento da parte da planta a ser utilizada está correto.

O modo de obter a planta citada pelas mães foi "em algum tipo de mercado" pela maioria, 31 (40\%) na instituição A e 37 (48\%) na instituição B; 14 (18\%) mães afirmaram conseguir em casa e 14 (18\%) com vizinhos. Esses dados nos levam a questionar se essas plantas vendidas em mercado são confiáveis, já que
O uso da fitoterapia no cuidado de crianças com até cinco anos em áreas central e periférica da cidade de São Paulo 
não existe nenhum controle de qualidade, pois na nossa prática, ao olharmos os saquinhos em que são vendidas, não encontramos selos de controle de alguma agência nacional ou regional incumbida de verificar se o acondicionamento é adequado, se a planta é real- mente a que está indicada no rótulo, se a colheita foi feita adequadamente, e outras avaliações importantes para um bom preparo e resultado satisfatório do uso.

$\mathrm{O}$ índice de satisfação com o efeito da planta pode ser visto na figura 4 .

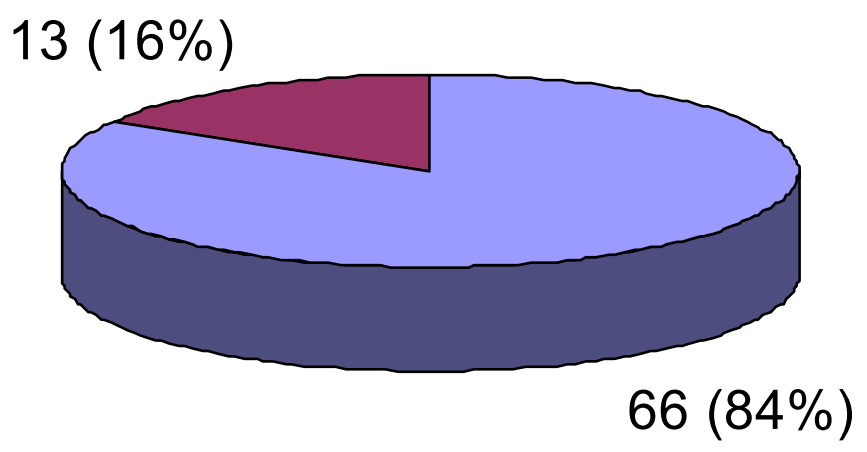

$\square$ Surtiram Efeito $\square$ Não Surtiram Efeito

Figura 4 - Índice de satisfação na utilização da fitoterapia em crianças de até cinco anos em dois Centros de Saúde da cidade de São Paulo(São Paulo, 2001)

Como mostra a figura 4, $66(84 \%)$ mães estão satisfeitas com o resultado da utilização das plantas, o que ressalta a eficácia da fitoterapia quando utilizada de maneira adequada. O conhecimento dos tipos e das conseqüências das doenças, das práticas e atitudes populares relacionadas à saúde das pessoas, assegurará ao enfermeiro uma maior segurança para aproveitar o que for benéfico, ter uma atitude neutra para o que for inócuo e procurar educar a população para não usar o que lhe for prejudicial ${ }^{(10)}$.

\section{CONSIDERAÇÕES FINAIS}

De acordo com os objetivos do trabalho, verificamos que 79 (66\%) mães de crianças de até cinco anos de idade que freqüentam os dois Centros de Saúde da cidade de São Paulo (um na região central e outro na região periférica) estão se utilizando da fitoterapia para o cuidado de seus filhos na cólica intestinal, sintomas de gripe e para tranqüilizá-los. Esse dado nos surpreendeu, pois esperávamos uma utilização maior na região periférica da cidade, imaginando que a população de menor poder aquisitivo, atendida na periferia, se utilizasse de recursos naturais para seus problemas. Vimos, porém, que algumas ervas (a camomila, a erva-doce e a hortelã) são tradicionalmente usadas em crianças, sendo seu conhecimento passado de geração para geração, independente da própria indicação que o profissional de saúde faça no atendimento da criança.
Os achados reforçam nossa crença da importância dos profissionais, e especialmente nós enfermeiros, conhecermos corretamente a fitoterapia como prática complementar no cuidado dos nossos clientes, para que possamos orientá-los sobre a forma adequada do cultivo, conservação e preparo das ervas.

É realmente necessário que se investigue e demonstre para que serve, e como utilizar a fitoterapia de maneira satisfatória e eficaz. Para isso, o número de pesquisas vem aumentando dia-a-dia e, como exemplo, citamos o interesse da Fundação de Amparo à Pesquisa do Estado de São Paulo - FAPESP, em pesquisas que visam descobrir novas drogas usadas por índios do Tocantins e que estão sendo estudadas na Unifesp para comprovar o seu poder de cura ${ }^{(14)}$.

Realizando levantamento com a população sobre seus hábitos caseiros de se autocuidar, também colaboramos com as frentes de pesquisas da fitoterapia, uma vez que o profissional enfermeiro pode ser elemento vital na preservação da sabedoria popular, integrando as trocas de conhecimento e enriquecendo os desdobramentos da validação científica de fitoterapia. 
(1) Castellano O. Introdução à fitoterapia. São Paulo: EDUSP; 1981.

(2) Comissão Interministerial de Planejamento e Coordenação. Resolução $n^{\circ} 8$. Implanta a prática de fitoterapia nos Serviços Públicos de Sáude. Diário Oficial da República Federativa do Brasil, Brasília, 26 jun 1988. Seção 1.

(3) França SC. Plantas contra tuberculose. Pesquisa FAPESP 2001; 28(6):40-1.

(4) Marcondes E. Pediatria básica. $7^{\mathrm{a}}$ ed. São Paulo: Savier, 1987.

(5) Medeiros LCM. As plantas medicinais e a enfermagem - a arte de assistir, de curar, de cuidar e de transformar os saberes.[tese]. Rio de Janeiro (RJ): Escola de Enfermagem Anna Néri/ UFRJ; 2001

(6) São Paulo (cidade). Comunicado da Secretaria Municipal da Saúde 001/2001. Diretrizes gerais para Secretaria Municipal da Saúde sobre Medicina Tradicional Chinesa: documento 1. Diário Oficial do Município. São Paulo, 25 jan 2001.p.10-12.

(7) Moss TM. Herbal medicine in the emergency department: a primer for toxicities and treatment. J Emerg Nurs 1998;24(6):509-13.

(8) Nogueira MJC. Fitoterapia popular e enfermagem comunitária. [tese]. São Paulo (SP): Escola de Enfermagem da USP; 1983.
(9) Nogueira MJC. Fitoterapia: a volta à natureza. Enfoque 1984; 12(1):8-11.

(10) Souza D, Silva MJP. O holismo espiritualista como referencial teórico para o enfermeiro. Rev Esc Enferm USP 1992; 26(2):235-42.

(11) Barbosa MA. A utilização de terapias alternativas por enfermeiros brasileiros. [tese]. São Paulo(SP):Escola de Enfermagem da USP; 1994.

(12) O' Neil CK. Herbal medicine getting beyond the hype. Nurs 1999; 29(4): 58-61.

(13) Organização Mundial da Saúde. Fundo das Nações Unidas para a Infância. Cuidados primários da Saude: relatório da Conferência Internacional sobre cuidados primários de Saúde. Alma. Ata, URSS, 6-12 de set 1978. Brasília: UNICEF, 1979.

(14) Pivetta M. Fitoterápicos, as lições de Krahô. Pesquisa FAPESP 2001; (70):40-5.

(15) Seravalle L. Introdução à discussão sobre o ensino de práticas alternativas em saúde. Saúde Debate 1996; 51:82-8.

(16) Atividades em terapias alternativas. Bol Inf COREN 1995; 18(4).

(17) Vidigal M. Terapias alternativas: receitas naturais para manter o corpo saudável e bonito. São Paulo: Europa; 1999.
O uso da fitoterapia no cuidado de crianças com até cinco anos em áreas central e periférica da cidade de São Paulo

\section{Anexo - Roteiro da entrevista: O Uso da Fitoterapia em crianças}

1.A Senhora utiliza ou alguma vez utilizou plantas medicinais para o tratamento de doenças em seus filhos?

$$
\text { ( ) } \operatorname{sim} \text { ( ) não }
$$

2.Se sim, qual planta utilizou e para qual (is) problema de saúde?

3.Como foi que teve acesso ao conhecimento dessas plantas medicinais no tratamento das doenças ou desses problemas?

( ) com profissional da saúde, qual:

( ) em casa, com os pais ou avós ( ) em livros ou revistas

( ) de acordo com crenças ou tradições ( ) vizinhos, conhecidos, amigos （ )outros,

4.Como essas plantas eram usadas?

Plantas:

( ) chás ( ) tinturas ( ) xaropes ( ) óleos $\quad($ ) pomadas

( ) cataplasmas ( ) cápsulas ( ) cápsulas

5.Como foram obtidas as plantas utilizadas:

( ) em plantações da própria casa ( ) com vizinhos

( ) comprados em algum tipo de mercado ( ) vendedor de rua ( ) outros,

6. Essas plantas surtiram o efeito desejado?

( ) $\operatorname{sim}$ ( ) não, porque: 